Journal of Advanced Research in Fluid Mechanics and Thermal Sciences

Journal homepage: www.akademiabaru.com/arfmts.html ISSN: $2289-7879$

\title{
A Study of The Developing Archimedes Screw as A Turbine
}

\author{
Dewi Puspita Sari ${ }^{1}$, M. A. Ade Saputra ${ }^{2}$, Imam Syofii ${ }^{1}$, Dendy Adanta ${ }^{2, *}$ \\ 1 Study Program of Mechanical Engineering Education, Faculty of Education, Universitas Sriwijaya, Indralaya-30662, South Sumatera, Indonesia \\ Department of Mechanical Engineering, Faculty of Engineering, Universitas Sriwijaya, Indralaya-30662, South Sumatera, Indonesia
}

ARTICLE INFO ABSTRACT

\section{Article history:}

Received 5 June 2021

Received in revised form 23 July 2021

Accepted 5 August 2021

Available online 10 September 2021

\section{Keywords:}

Pico hydro; Archimedes screw turbine; independent power plant; electricity

\begin{abstract}
Electricity plays an imperative role in improving the rural or remote community economic growth and quality of life. The pico hydro type Archimedes screw turbine (AST) is considered an independent power plant in rural or remote areas. The advantages of the AST are friendly to aquatic biota, the high and stable efficiency (electrical efficiency of $30 \%$ to $49 \%$ ), and can operate in a run of river conditions. However, although this technology has been studied \pm two decades, there is still no theory explaining the relationship between conversion energy, the geometry of screws, and efficiency. Therefore, the development of Archimedes screw focuses on the role of a converter water energy categorized as the environmentally friendly power plant. Thus, this paper aims to describe the future work required for the AST so that the basic principles and empirical theories are found. Based on reviews, the AST design can use Rorres and Muller \& Senior analysis, AC generators with a pulley and toothed belt transmission systems, and do not immerse the outflow bucket side in the water. Furthermore, for AST to be better, several studies need to be done such as the method of manufacturing precision screws, the effect bubbles in the bucket and how to avoid them, determination optimum of the head and screw length using the slope angle, and investigation of the ratio of the inlet velocity with the angular velocity of a wheel on performance to avoid overflow leakage due to loading.
\end{abstract}

\section{Introduction}

Currently, electricity plays an imperative role in improving rural or remote community economic growth and quality of life [1]. The electricity in rural or remote areas increases lighting time (increasing hours of productivity), triggering regional business development [1]. Therefore, the availability of electricity in rural or remote areas is a form of encouragement to increase economic productivity [2].

Rural or remote areas are difficult to access, making the construction of electricity grids to connect and transmit electrical energy to the regions becoming increasingly complex and expensive [3]. A wise solution to resolve this problem is to utilize each region's potential energy as an energy source for independent power plants [4]. Based on studies, some developing countries use pico hydro

\footnotetext{
* Corresponding author.

E-mail address: dendyadanta@ymail.com
}

https://doi.org/10.37934/arfmts.87.1.151160 
turbines as independent power plants in rural or remote areas, such as Cameron [5], Honduras [6], Indonesia [7], Laos [8], Nepal [9], and Rwanda [10-11]. Furthermore, based on life cycle costs assessment, pico hydro is 8 to 10 times more profitable than a wind turbine and solar photovoltaic [4].

The problem with implementing pico hydro is not friendly to aquatic biota [12]. The fast-rotating runner can kill the fish that passes through it [12]. For this reason, Archimedes turbines are considered because aquatic organisms such as fish can still swim through gaps in the turbine blades [13-15].

Archimedes first made Archimedes screws. Initially, the Archimedes screw was used as a water pump called Archimedes pump (see Figure 1). The screw the Archimedes pump are blades that form a helix on a cylindrical shaft [17]. The screw in the Archimedes pump is covered by a semi-closed or closed cylinder [17]. In 1999, Brada [18] utilized Archimedes screw for generated electricity. The Archimedes screw turbine (AST) used by Brada resembles the Archimedes pump [18]. Brada's [17] test results (reported by Müller and Senior [16]) received the attention of researchers in the field of hydropower to study the Archimedes screw as a turbine. The test results show several advantages of Archimedes screw as turbines, such as relatively high efficiency of $55 \%$ until $80 \%$ under low head operating conditions [17-18], and can run on large discharges [17-18]. However, there is still no theory explaining the relationship between conversion energy, the geometry of screw, and efficiency. The Archimedes screw focuses on the role as a converter water energy categorized as the environmentally friendly power plant for development. Therefore, this paper aims to describe the future work required for the AST so that the basic principles and empirical theories are found.

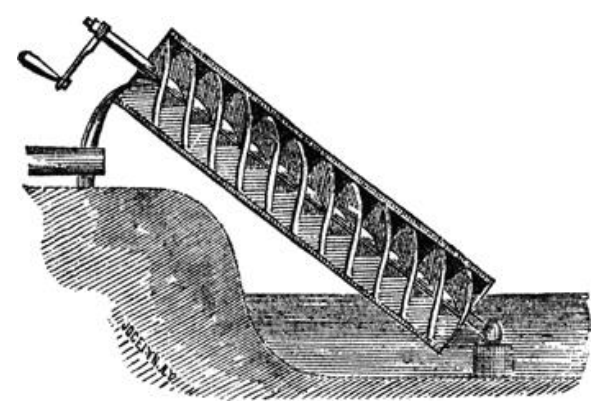

(a) Three-dimension [16]

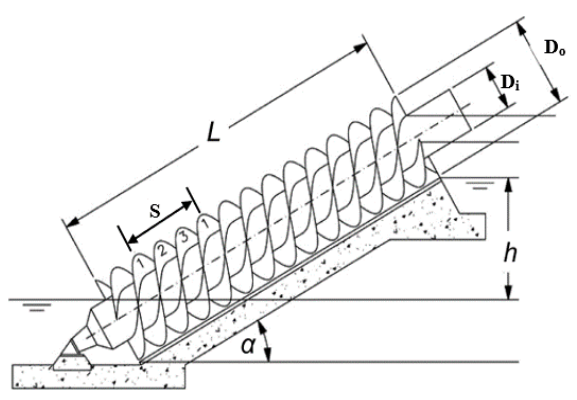

(b) Two-dimension [17]

Fig. 1. Illustration of the screw the Archimedes pump

\section{Terminology of Archimedes Screw Turbine}

The term used in the ASTs is buckets: the volume of water occupying chutes; chutes: two blades bound the volume; and pitch: the blade length is one round or one period. The detailed terminology of the AST is available in Table 1, and its term can be seen in Figure 2. 


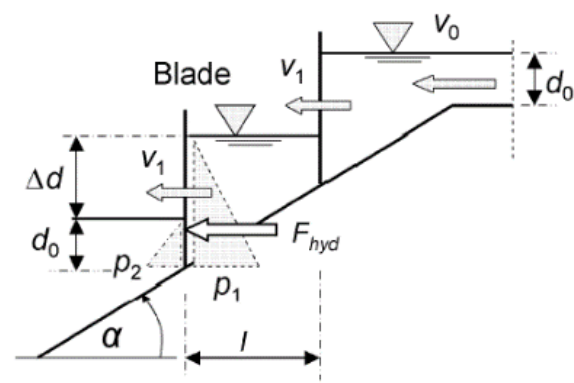

(a) Side view

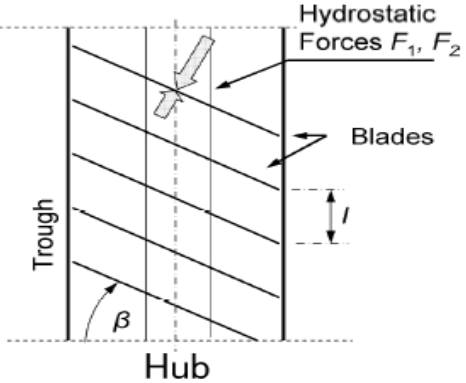

(b) Front view

Fig. 2. Illustration of energy conversion in Archimedes turbine Müller and Senior [17]

\section{Table 1}

Terminology in AST

\begin{tabular}{ll}
\hline Symbols & Definition \\
\hline$\alpha$ & The slope of turbine angle \\
$R_{o}$ & Radius outer \\
$D_{o}$ & Diameter outer \\
$M$ & Number of rotations of the screw helix \\
$R_{i}$ & Radius inner \\
$V_{u}$ & The volume of water over a period \\
$L$ & Length of screw \\
$S$ & Pitch length \\
$\lambda$ & Pitch ratio \\
$\alpha$ & The slope of turbine angle \\
$P_{h y d r o}$ & Potential power \\
$P$ & Total power turbine \\
$P_{o}$ & Power one blade \\
$\mathrm{I}$ & The horizontal distance between the blade \\
$\Delta d$ & Difference of water level between two blades \\
$V_{i}$ & Velocity water in the turbine \\
$V_{o}$ & Velocity inlet \\
$k$ & Ratio Ro to Ri \\
$V$ & Volume ratio \\
\hline
\end{tabular}

\section{Characteristic of Archimedes Screw Turbines}

Initially, allegedly the main forces that rotate the wheel of ASTs are the weight of water [18-19]. However, some studies conclude that water weight contribution does not significantly affect the wheel rotation because the water in the bucket is not much and looks silent. The motion of water goes downstream like displacement [20]. In addition, the direction of water movement due to gravity with the wheel's rotation is opposite [17]. Hence the AST is driven by hydrostatic pressure by water [17-21]. Müller and Senior [17] suspected the AST absorbs is hydrostatic pressure (see Figure 2). The hydrostatic pressure occurred because of differences in each blade's water level (see Figure 2) [17]. Based on this assumption, Müller and Senior [17] made modeling with two dimensional (Figure 2) analysis for calculation the efficiency $(\eta)$ of AST.

$\eta=\frac{2 n+1}{2 n+2}$

where $\mathrm{n}$ is $\mathrm{d}_{0} \cdot \Delta \mathrm{d}$ and the magnitude of $\Delta \mathrm{d}$ is $\mathrm{I}^{\cdot} \tan \alpha$. Then, the output power $(\mathrm{P})$ is 
$P=\eta \cdot P_{h y d r o}$

$P_{h y d r o}=\rho \cdot g \cdot d_{o} \cdot V_{o} \cdot m \cdot \Delta d$

Based on Eq. (3), the efficiency ( $\eta$ ) of AST is affected by the turbine slope angle ( $\alpha$ ) and pitch (number of rotation of screw) [17].

The optimum dimension for a case of the AST is still unknown. Therefore, the alternative currently used to determine it is the volume optimization method proposed by Rorres [16]. Rorres [16] uses three non-dimensional parameters determined by variations in the number of blades to obtain the optimal bucket volume. The three non-dimensional parameters are: volume ratio $(v)$, pitch ratio $(\lambda)$ and radius ratio $(\mathrm{k})[16]$.

$v=\frac{V_{u}}{V \cdot R_{o}^{2} \cdot \Lambda}$

$\lambda=\frac{\Lambda}{2 \cdot \pi \cdot R_{o}}$

$k=\frac{R_{i}}{R_{o}}$

where $\wedge$ is $2 \cdot \pi \cdot R$.

\section{Archimedes Screw Turbine Studies}

Rorres [16] summarized the AST optimization based on Nagel's [22] analysis. Rorres [16] divides the Archimedes turbine parameters into two: internal parameters such as inner radius, number of blades, and pitch of the blades; and external parameters such as outer radius, length, and the $\alpha$ angle. The external parameters determine how much water will be filled, while the external parameters optimize the performance. Defined optimization by maximizing the volume of water lifted can be determined using the inner radius and pitch [16].

Based on Rorres's [16] analysis, the $\alpha$ angle for obtaining the highest efficiency. To prove this, Havendri and Arnif [23] examined the angle of the screw. Experiments were carried out at the head of 1.1. $m$ and with three variations of the angle of the screw, namely $23^{\circ}, 26^{\circ}$, and $29^{\circ}$ [23]. Based on the results, there is a relationship between output power $(P)$ and discharge $(Q)$ with the angle of the screw. However, this results not a final conclusion because it shows that the greater the $\alpha$ angle of the screw, the efficiency increases too (highest efficiency at $29^{\circ}$ ) [23].

The difficulty of the optimization proposed by Rorres [16] initiated Müller and Senior [17] to offer a simplification theory (see Figure 2). The simplification theory to the more accessible understanding of the principle of the AST [17]. Müller and Senior [17] presumed that the AST dominant absorb hydrostatic force.

Nuernbergk and Rorres [24] developed a simple analytical model to account for the leakage due to the gap between the screw with the wall and water overflow to the next bucket. Nuernbergk and Rorres [24] state that this analytical model can determine the optimum operation of this turbine, such as the optimum $\alpha$ angle and the volume capacity of the lift without overflow. Raza et al., [25] 
were used this analytical model to study the hydraulic behavior of the AST: increasing the $\alpha$ angle causes discharge $(Q)$ but the efficiency decreases, vice versa.

In 2014, there was one AST in North America (the 7 kW Flecher's screw installed in 2013) [26]. Lyons [25] improved the mathematical model of the AST initiated by Müller and Senior [16] and Rorres [15]. Simultaneously, Lyons [25] proposes a mathematical model in determining the AST efficiency ( $\eta$ ). Lyons [26] created a calculation model to determine the volume of water in the bucket and different levels of water in the upper and lower buckets by three-dimensional (3D) analysis. The calculation is accurate if losses at the screw outlet are minimized by keeping the outlet water level at an average level (e.g., $50 \%$ or $60 \%$ of the height of the screw outlet) [26]. When water levels were lower, power output was close to the same (power output decreased when checked carefully) [26]. However, when the water level at the outlet was much higher, then power output and efficiency both decreased noticeably [26]. However, the deficiency of the mathematical model has not been able to accurately represent the effect of leakage losses that occur due to gaps between the bucket and the wall [26].

Although this turbine has high efficiency (70\%) [26] and fish-friendly [14], however, the precision manufacturing of screws is complex. A possible alternative to build precision screws is to use a 3D print machine. The feasibility study of a 3D print machine for making screws with polylactic acid and epoxy was carried out [27]. Based on results, Lee et al., [27] stated that the materials polylactic acid and epoxy could be used where it is capable of generating $123 \mathrm{~W}$ ( $n$ of $71 \%$ ) in operating conditions with a discharge $(Q)$ of $0.04 \mathrm{~m}^{3} / \mathrm{s}$ and a head $(H)$ of $0.4 \mathrm{~m}$ (pico scale). Furthermore, investment costs using the polylactic acid and epoxy for manufacturing of screw are cheaper than using metals, only \pm USD 277. However, the disadvantage of using these materials is that the screw age only two years [27].

The physical phenomenon in the AST has not yet become a concern, whereas this is important to know the hydraulic behavior. Based on this, Saroinsong et al., [28] examined the effect of the vortex on the performance of AST. Based on the results, the vortex affects the performance of this turbine [28]. Furthermore, since the water in the bucket formed a vortex due to shaft rotation, the vortex inhibits shaft rotation [28]. Therefore, reducing the $\alpha$ angle can lessen the vortex [28].

The mathematical model proposed by Lyons [26] is no accurate even though it has been studied comprehensively, where this motivated Kozyn and Lubitz [29] to improve Lyons [26] analysis. In calculating performance, Kozyn and Lubitz [29] added an examination of power losses due to friction in bearing and internal hydraulic and effect of submersion outlets. The friction in internal hydraulic and submersion outlets is based on open channel flow concepts and the Darcy-Weisbach equation. In contrast, the friction in the bearing is based on the Borda-Carnot equation [29]. The analysis improvement was successful because the difference in calculation with experimental data was only $14 \%$ [29].

Rorres [16] and Müller and Senior [17] stated that the $\alpha$ angle is a parameter that determines AST performance because it can cause overflow to the next bucket. Havendri and Arnif [22] have proven this hypothesis, but the reported results have doubtful results. Therefore, Yulistiyanto et al., [30], Khami and Akhyan [31], Erinofiardi et al., [32-33], Siswantara et al., [20,-34], and Dellinger et al., [3536] motivated to study the effect of the $\alpha$ angle on performance such as.

Yulistiyanto et al., [30] investigated the effect of discharge and the $\alpha$ angle on performance to prove the simplification theory [14]. Based on the results, there is a correlation between wheel rotation with the $\alpha$ angle. The $\alpha$ angle increases, making the efficiency $(\eta)$ increase, while the discharge $(Q)$ increases, making the efficiency $(\eta)$ decrease [30]. The large discharge $(Q)$ makes the efficiency decrease allegedly because a lot of water overflow to the next bucket (losses), so it's not absorbed [30]. 
Khami and Akhyan [31] examined the effect of the $\alpha$ angle on the performance of the turbine and pitch size on wheel rotation. Based on the results, the $\alpha$ angle and pitch size influenced turbine performance and wheel rotation, respectively [31]. Further studies on pitch size can be used as a variable to determine the AST optimization from these results. Since the higher the pitch size, the wheel rotation faster, and cause the torque will get smaller.

Erinofiardi et al., [32-33] investigated the $\alpha$ angle of $22^{\circ}, 30^{\circ}$, and $40^{\circ}$. Erinofiardi et al., [32-33] manufacture the AST using the simplification theory initiated by Müller and Senior [17]. As the results, as the $\alpha$ angle increases, the wheel rotation increases, the torque decreases, and efficiency decreases [32]. The turbine is not working optimally (decrease in efficiency) allegedly due to the gap between the wheel with the wall is large of $5 \mathrm{~mm}$, and the bucket is not filled because of low discharge $(1.2 \mathrm{l} / \mathrm{s})$ [32]. Consequently, the efficiency $(\eta)$ is lower than predicted (analysis) [32-33]. Hence, the simplification theory is too simple, where many loss factors are not considered, so the investigation is not accurate [33].

Due to Erinofiardi et al., [32] reports is not satisfying, Siswantara et al., [20-34] also investigated the effect of the $\alpha$ angle on overflow leakage, where the analysis in the $\alpha$ angle of $36^{\circ}$ until $44^{\circ}$. Based on the results, the overflow leakage does affect the turbine efficiency but not the dominant effect, were in the angle of $36^{\circ}$ efficiency of $30 \%$ and $44^{\circ}$ the efficiency of $27.5 \%$ [20]. Contradicts to Rorres's [16] analysis, the overflow leakage should make efficiency go down drastically. Furthermore, overflow leakage occurs because of the large the $\alpha$ angle, but it can also be because of the large load received by the turbine [34]. In addition, the high loads received by the turbine also cause bubbles to form in buckets. In hydropower generation, the appearance of bubbles should be avoided because cavitation can occurs [37]. However, there has not been a comprehensive study of the effect of the $\alpha$ angle on the formation of bubbles in the AST bucket [34].

Dellinger et al., [35-36] investigated the effect of the gap leakage using the computational fluid dynamics (CFD) method and effect the $\alpha$ angle of $10^{\circ}$ until $38^{\circ}$ and number of blades on the performance of the AST. Based on the results, the $\alpha$ angle $\left(10^{\circ}\right.$ until $\left.38^{\circ}\right)$ affects the AST performance [35-36], were in the angle of $10^{\circ}$ efficiency of $85 \%$ and $38^{\circ}$ the efficiency of $80.5 \%$ [35]. As the results, confirmed the $\alpha$ angle is the effect on the AST performance [20-34-36]. The optimum of the $\alpha$ angle of $15.5^{\circ}$ [36] is optimum; however, the $\alpha$ angle is still to be reviewed because the simulation in the $\alpha$ angle of $15.5^{\circ}$ does not yet validate. The turbine number of blades of 3,4 , and 5 are compared to determine its optimum [36]. They have not yet concluded because the more the blade, the greater the efficiency [36]. Since in the angle of $20^{\circ}$ and $24^{\circ}$, the 5 blades generated more power than 3 and 4 blades. Whereas in the angle $10^{\circ}$, the 3 blades generated more power than 4 and 5 blades. Furthermore, the Dellinger et al., [35-36] study can be used as a reference for the CFD study in the AST because the error of its results with experimental is small (less than 2\%). Table 2 summarize studies in the AST. 
Table 2

Summary of studies in the AST

\begin{tabular}{|c|c|}
\hline Particulars & Specifications \\
\hline Rorres [16] & Optimization the AST \\
\hline Havendi and Arnif [38] & Effect the angle of screw \\
\hline Müller and Senior [17] & Simplification theory \\
\hline Yulistiyanto et al., [30] & $\begin{array}{l}\text { Investigated the effect of discharge and the } \alpha \text { angle on performance to prove the } \\
\text { simplification theory [17] }\end{array}$ \\
\hline Nuernbergk and Rorres [24] & Model analytic for water inflow in the AST \\
\hline Raza et al., [25] & Calculation of the performance of the AST using Simulink MATLAB \\
\hline Lyons [26] & 3D analysis of water volume in the AST bucket \\
\hline Khami and Akhyan [31] & Investigated the effect of the $\alpha$ angle \\
\hline Lee et al., [27] & Feasibility study 3D printing machines for manufacturing the ASTs wheel \\
\hline Saroinsong et al., [28] & Effect of the vortex on the performance of the AST \\
\hline Harja et al., [39] & Optimization volume bucket by Rorres model [16] \\
\hline Kozyn and Lubitz [29] & Modeling losses (improvisation Lyons [26] study) \\
\hline Erinofiardi et al., [32,33] & Investigated the $\alpha$ angle of $22^{\circ}, 30^{\circ}$ and $40^{\circ}$ \\
\hline Siswantara et al., $[20,34]$ & $\begin{array}{l}\text { Analysis of the effect of overflow leakage and investigated the } \alpha \text { angle of } 36^{\circ} \text { until } \\
44^{\circ}\end{array}$ \\
\hline Dellinger et al., $[35,36]$ & $\begin{array}{l}\text { Analysis gap leakage using computational fluid dynamics (CFD) method and } \\
\text { investigation of effect the } \alpha \text { angle of } 10^{\circ} \text { until } 38^{\circ} \text { and number of blades }\end{array}$ \\
\hline
\end{tabular}

\section{Discussions}

AST studies have confirmed the effect of the $\alpha$ angles. Increasing the $\alpha$ angles decreases efficiency, although the reduction in efficiency is low [20-32-36]. By CFD study, Dellinger et al., [36] report that the most efficient angles tested occurs at $15.5^{\circ}$. However, this inference is doubt. Since the latest information from Romney Weir (United Kingdom), the optimum of the $\alpha$ angles for the large-scale screw is $22^{\circ}$, which agrees with YoosefDoost and Lubitz [40]. The study of the influence of the $\alpha$ angle on performance and investment cost should be addressed [34]. Suppose the optimum operation conditions for AST at an $\alpha$ angle of $22^{\circ}$ are verified. In that case, it will be adding the AST dimensional analysis because the relation of the head $(H)$ and length of the screw $(L)$ will be known. Since the optimum ratio of $H / L$ is not yet known, the analysis initiated by the Rorres [16] is difficult to apply.

Based on losses analysis [20], the overflow leakage is avoided by the $\alpha$ angles, not extremes. However, the experimental results show that the dominant load makes overflow leakage, not the $\alpha$ angles (see Figure 3) [20-34]. Based on Figure 3, more load will produce a more dominant overflow [34]. For a load of $300 \mathrm{~W}$ (Figure 3(a)), overflow occurs in two zones: between near the wall with the blade tip and the center of the shaft. While, in a load of $100 \mathrm{~W}$ (Figure 3(b)), overflow only occurs in between near the wall with the blade tip. Overflow leakage becomes higher when the loading was increasing because the wheel rotation was slowing down. Hence a large load requires a large torque. Therefore, the discussion about the effects of loading on overflow should be special attention to add insight into the character of the AST. 


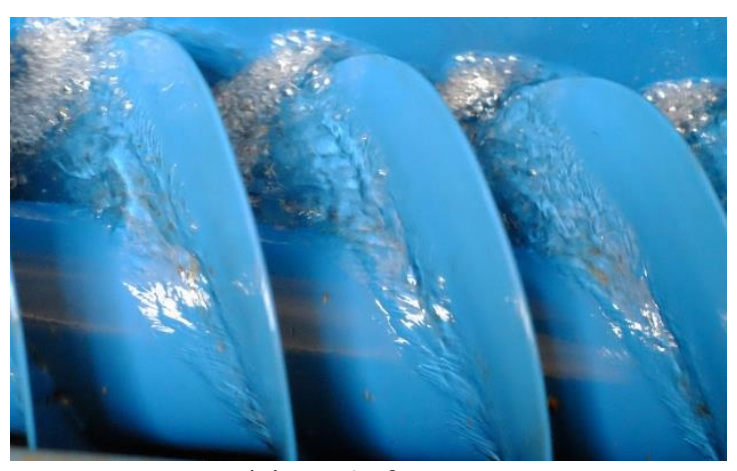

(a) Load of $300 \mathrm{~W}$

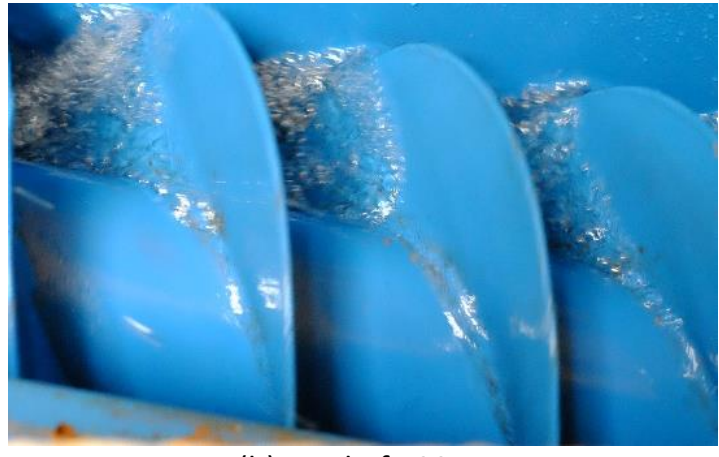

(b) Load of $100 \mathrm{~W}$

Fig. 1. Overflow leakage visualization [20-34]

The rotation of the AST is low, around 60 until $130 \mathrm{rpm}$ [16-41]. A turbine with a low rotation is suitable to use a direct current (DC) generator because it still produces electricity [42-43]. However, based on testing, the alternating current $(A C)$ generator generating higher power than the $D C$ generator, the difference of $10 \%$ [41]. Therefore, based on the report, DC generators have higher losses than AC generators. High losses are suspected because the transmission system used the DC generator, flat belt for DC generator, and toothed belt for AC generator [41]. Two possibilities that cause DC generator losses are increased: the connection of the DC generator to the power supply is more complex, and splashing water into the flat belt transmission system increases slip. Therefore, the suitable generator for AST type AC with transmission systems of toothed belt [20-34-41].

AST is suitable for under low head $(<3 \mathrm{~m})$ conditions because it is electrical efficiency is stable and high, ranging between 30\% until 49\% [20-32-34]. Furthermore, AST can work on low and high discharge conditions, $0.01 \mathrm{~m}^{3} / \mathrm{s}$ [20-34] until $10 \mathrm{~m}^{3} / \mathrm{s}$ [41]. From the aspect of civil work, AST is appropriate for remote areas because the head and discharge conditions of the operation are run of river, where does not require complex civil construction. Thus, the study of AST is important to be continued as an effort to improve the welfare of peoples in remote areas.

\section{Conclusion}

The AST is a turbine capable of operating with high and stable efficiency under the low head and high range discharge. This able for implemented in remote areas are difficult to access by national grid electricity. The proposed design by Rorres [16] and Muller and Senior [17] to manufacture the AST analysis, AC generator [41], transmission systems using toothed belts [41], and do not immerse the outflow bucket side in the water [26].

For the AST increase its performance, there are several important studies to carried out such as the method of manufacturing precision screws, the effect of the bubbles in the bucket and how to avoid them, determination of optimum the $h / L$ ratio using the $\alpha$ angle, and investigation of the inlet velocity with the angular velocity of the wheel on performance to avoid overflow leakage due to loading.

\section{Acknowledgment}

The authors would like to thank the Research and Community Service Institute (LPPM) of Universitas Sriwijaya as a funder with grant no. 0019.29/UN9/SB3.LP2M.PM/2020, and to Assoc. Professor William David Lubitz, Ph.D., P.Eng. from the University of Guelph, Canada, suggests and input writing this paper. 


\section{References}

[1] Institute Bisnis dan Ekonomi Kerakyatan J I C A. Manual Pembangunan PLTMH (Jakarta). 2003.

[2] Khattak, M. A., NS Mohd Ali, NH Zainal Abidin, N. S. Azhar, and M. H. Omar. "Common Type of Turbines in Power Plant: A Review." Journal of Advanced Research in Applied Sciences and Engineering Technology 3, no. 1 (2016): 77100.

[3] Razali Ritonga. Kebutuhan Data Ketenagakerjaan untuk Pembangunan Berkelanjutan (Jakarta). 2015.

[4] Adanta, Dendy, Budiarso Budiarso, and Ahmad Indra Siswantara. "Assessment of turbulence modelling for numerical simulations into pico hydro turbine." Journal of Advanced Research in Fluid Mechanics and Thermal Sciences 46, no. 1 (2018): 21-31.

[5] Ho-Yan, Bryan. "Design of a low head pico hydro turbine for rural electrification in Cameroon." PhD diss., 2012.

[6] Thomas, Brian. "Pico-hydropower franchising in rural Honduras." International Journal for Service Learning in Engineering, Humanitarian Engineering and Social Entrepreneurship 6, no. 1 (2011): 46-63. https://doi.org/10.24908/ijsle.v6i1.3213

[7] Sari, Dewi Puspita, Helmizar Helmizar, Imam Syofii, Darlius Darlius, and Dendy Adanta. "The Effect of the Ratio of Wheel Tangential Velocity and Upstream Water Velocity on the Performance of Undershot Waterwheels." Journal of Advanced Research in Fluid Mechanics and Thermal Sciences 65, no. 2 (2020): 170-177.

[8] Vicente, Silvia, and Hans Bludszuweit. "Flexible design of a pico-hydropower system for Laos communities." Renewable energy 44 (2012): 406-413. https://doi.org/10.1016/i.renene.2012.02.011

[9] Adhikari, Pradhumna, Umesh Budhathoki, Shiva Raj Timilsina, Saurav Manandhar, and Tri Ratna Bajracharya. "A study on developing pico propeller turbine for low head micro hydropower plants in Nepal." Journal of the Institute of Engineering 9, no. 1 (2013): 36-53. https://doi.org/10.3126/jie.v9i1.10669

[10] Gladstone, Scott, Victoria Tersigni, Kevin Francfort, and Julie Ann Haldeman. "Implementing pico-hydropower sites in rural Rwanda." Procedia Engineering 78 (2014): 279-286. https://doi.org/10.1016/i.proeng.2014.07.068

[11] Pigaht, Maurice, and Robert J. Van der Plas. "Innovative private micro-hydro power development in Rwanda." Energy policy 37, no. 11 (2009): 4753-4760. https://doi.org/10.1016/j.enpol.2009.06.039

[12] Tang, Weiyao, Zongmin Li, and Yan Tu. "Sustainability risk evaluation for large-scale hydropower projects with hybrid uncertainty." Sustainability 10, no. 1 (2018): 138. https://doi.org/10.3390/su10010138

[13] Kibel, P. "Archimedes screw turbine fisheries assessment. Phase II: Eels and kelts." Aquacult. Eng 1 (2008): $297-310$.

[14] Landustrie. Landustrie Hydropower Screws (Natherland: Landustrie). 2012.

[15] Piper, Adam T., Paula J. Rosewarne, Rosalind M. Wright, and Paul S. Kemp. "The impact of an Archimedes screw hydropower turbine on fish migration in a lowland river." Ecological Engineering 118 (2018): 31-42. https://doi.org/10.1016/i.ecoleng.2018.04.009

[16] Rorres, Chris. "The turn of the screw: Optimal design of an Archimedes screw." Journal of hydraulic engineering 126, no. 1 (2000): 72-80. https://doi.org/10.1061/(ASCE)0733-9429(2000)126:1(72)

[17] Müller, Gerald, and James Senior. "Simplified theory of Archimedean screws." Journal of Hydraulic Research 47, no. 5 (2009): 666-669. https://doi.org/10.3826/ihr.2009.3475

[18] Brada, K. "Spiral turbine enables power generation by small hydropower plants; Wasserkraftschnecke ermoeglicht Stromerzeugung ueber Kleinkraftwerke." MM-Maschinenmarkt 105 (1999).

[19] Nagel, G., and K. A. Radlik. "Wasserförderschnecken [Water lifting screws] Bauverlag." Wiesbaden/Berlin [in German] (1988).

[20] Siswantara, Ahmad Indra, Rudias Harmadi, and Dendy Adanta. "Analysis of the Effects of Overflow Leakage Phenomenon on Archimedes Turbine Efficiency." In 2018 4th International Conference on Science and Technology (ICST), pp. 1-6. IEEE, 2018. https://doi.org/10.1109/ICSTC.2018.8528687

[21] Senior, James, Patrick Wiemann, and Gerald Muller. "The rotary hydraulic pressure machine for very low head hydropower sites." Proc. Hidroenergia (2008).

[22] Nagel, Gerhard. Archimedian Screw Pump Handbook: Fundamental Aspects of the Design and Operation of Water Pumping Installations Using Archimedian Screw Pumps. RITZ-Pumpenfabrik OHG, 1968.

[23] Havendri, Adly, and Irfan Arnif. "Kaji Eksperimental Penentuan Sudut Ulir Optimum Pada Turbin Ulir Untuk Data Perancangan Turbin Ulir Pada Pusat Listrik Tenaga Mikrohidro (PLTMH) Dengan Head Rendah." Sumber 1500 (2000): 1-35.

[24] Nuernbergk, Dirk M., and Chris Rorres. "Analytical model for water inflow of an Archimedes screw used in hydropower generation." Journal of Hydraulic Engineering 139, no. $2 \quad$ (2013): 213-220. https://doi.org/10.1061/(ASCE)HY.1943-7900.0000661

[25] Raza, Ali, Muhammad Saleem Mian, and Yasir Saleem. "Modeling of archimedes turbine for low head hydro power plant in simulink MATLAB." International Journal of Engineering Research \&technology (IJERT) 2, no. 7 (2013): 2471 2477. 
[26] Lyons, Murray. "Lab testing and modeling of Archimedes screw turbines." PhD diss., 2014.

[27] Lee, Kyung Tae, Eun-Seob Kim, Won-Shik Chu, and Sung-Hoon Ahn. "Design and 3D printing of controllable-pitch archimedean screw for pico-hydropower generation." Journal of Mechanical Science and Technology 29, no. 11 (2015): 4851-4857. https://doi.org/10.1007/s12206-015-1032-y

[28] Saroinsong, Tineke, Rudy Soenoko, Slamet Wahyudi, and Mega Nur Sasongko. "Fluid flow phenomenon in a threebladed power-generating Archimedes screw turbine." Journal of Engineering Science and Technology Review 9, no. 2 (2016): 72-79. https://doi.org/10.25103/jestr.092.12

[29] Kozyn, Andrew, and William David Lubitz. "A power loss model for Archimedes screw generators." Renewable Energy 108 (2017): 260-273. https://doi.org/10.1016/i.renene.2017.02.062

[30] Lisdiyanti, L., Y. Hizhar, and B. Yulistiyanto. "Effect Of Flow Discharge And Shaft Slope Of Archimides (Screw) Turbin On The Micro-Hydro Power Plant." (2012).

[31] Khamdi, Nur, and Amnur Akhyan. "Pengaruh Pitch Terhadap Perputaran Pada Turbin Screw 3 Lilitan." Jurnal Teknik Elektro dan Komputer 2, no. 2 (2014): 181-188.

[32] Nuramal, Agus, Putra Bismantolo, Abhijit Date, Aliakbar Akbarzadeh, Afdhal Kurniawan Mainil, and Ahmad Fauzan Suryono. "Experimental study of screw turbine performance based on different angle of inclination." Energy Procedia 110 (2017): 8-13. https://doi.org/10.1016/i.egypro.2017.03.094

[33] Erinofiardi, Erinofiardi. "Preliminary design of Archimedean screw turbine prototype for remote area power supply." Journal of Ocean Mechanical and Aerospace Science and Engineering- 5, no. 03 (2014): 1-12.

[34] Siswantara, Ahmad Indra, Rudias Harmadi, and Dendy Adanta. "Investigation of the $\alpha$ angle's effect on the performance of an Archimedes turbine." Energy Procedia $156 \quad$ (2019): $458-462$. https://doi.org/10.1016/i.egypro.2018.11.084

[35] Dellinger, Guilhem, Pierre-André Garambois, Nicolas Dellinger, Matthieu Dufresne, Abdelali Terfous, Jose Vazquez, and Abdellah Ghenaim. "Computational fluid dynamics modeling for the design of Archimedes Screw Generator." Renewable Energy 118 (2018): 847-857. https://doi.org/10.1016/i.renene.2017.10.093

[36] Dellinger, Guilhem, Scott Simmons, William David Lubitz, Pierre-André Garambois, and Nicolas Dellinger. "Effect of slope and number of blades on Archimedes screw generator power output." Renewable Energy 136 (2019): 896 908. https://doi.org/10.1016/i.renene.2019.01.060

[37] Siswantara, Ahmad Indra, Budiarso Budiarso, Aji Putro Prakoso, Gun Gun R. Gunadi, Warjito Warjito, and Dendy Adanta. "Assessment of turbulence model for cross-flow pico hydro turbine numerical simulation." CFD Letters 10 , no. 2 (2018): 38-48.

[38] Havendri, Adly, and Irfan Arnif. "Kaji Eksperimental Penentuan Sudut Ulir Optimum Pada Turbin Ulir Untuk Data Perancangan Turbin Ulir Pada Pusat Listrik Tenaga Mikrohidro (PLTMH) Dengan Head Rendah." Sumber 1500 (2000): 1-35.

[39] Harja, Herman Budi, Halim Abdurrahim, Sigit Yoewono, and Hendi Riyanto. "Penentuan Dimensi Sudu Turbin dan Sudut Kemiringan Poros Turbin pada Turbin Ular Archimedes." Metal Indonesia 36, no. 1 (2016): 26-33. https://doi.org/10.32423/jmi.2014.v36.26-33

[40] YoosefDoost, Arash, and William David Lubitz. "Archimedes Screw Turbines: A Sustainable Development Solution for Green and Renewable Energy Generation-A Review of Potential and Design Procedures." Sustainability 12, no. 18 (2020): 7352. https://doi.org/10.3390/su12187352

[41] Dedić-Jandrek, Hrvoje, and Sandro Nižetić. "Small scale archimedes hydro power plant test station: Design and experimental investigation." Journal of cleaner production $231 \quad$ (2019): $756-771$. https://doi.org/10.1016/j.jclepro.2019.05.234

[42] Febriansyah, Dwijaya, Budiarso Budiarso, Warjito Warjito, Keizo Watanabe, and Dendy Adanta. "Storage system manufacturability, portability and modularity for a pico hydro turbine." Journal of Advanced Research in Fluid Mechanics and Thermal Sciences 51, no. 2 (2018): 209-214.

[43] Febriansyah, Dwijaya, and Dendy Adanta. "The effect of wheel and nozzle diameter ratio on the performance of a Turgo turbine with pico scale." Energy Reports 6 (2020): 601-605. https://doi.org/10.1016/i.egyr.2019.11.125 